\title{
A ESTABILIDADE PROVISÓRIA DA GESTANTE E O DIÁLOGO DA COERÊNCIA: UMA COMPREENSÃO FENOMENOLÓGICA
}

\author{
PROVISIONAL STABILITY OF THE PREGNANT EMPLOYEE AND THE \\ COHERENCE DIALOGUE: A PHENOMENOLOGICAL UNDERSTANDING
}

\section{LA ESTABILIDAD PROVISIONAL DE LA GESTANTE Y EL DIÁLOGO DE LA COHERENCIA: UNA COMPRENSIÓN FENOMENOLÓGICA}

\author{
FAUSTO SIQUEIRA GAIA \\ Doutorando em Direito do Trabalho pela Pontifícia Universidade Católica de São Paulo (PUC/SP). Mestre em Direitos \\ e Garantias Fundamentais pela Faculdade de Direito de Vitória. Vitória, Espírito Santo, Brasil. \\ http://lattes.cnpq.br/9097703481579476 / http://orcid.org/0000-0001-5609-2272 / faustogaia@yahoo.com.br
}

\begin{abstract}
RESUMO
O presente artigo realiza uma releitura do instituto da estabilidade provisória da empregada gestante nos contratos de trabalho por prazo determinado à luz dos princípios contratuais, como o da boa-fé subjetiva, da autonomia da vontade e da força obrigatória dos contratos, de modo a estabelecer os limites desta estabilidade provisória no emprego. Assentado na teoria do diálogo das fontes do Direito do Trabalho com o Direito Civil, tem-se que nos contratos de trabalho por prazo determinado a presunção relativa de despedida discriminatória da trabalhadora gestante sem justa causa, em situações de rescisão antecipada, pode ser afastada desde que apontadas as razões de ordem técnica, estrutural ou econômico-financeira que ensejaram a ruptura.
\end{abstract}

Palavras-chave: Estabilidade; Gestante; Limites; Princípios.

\begin{abstract}
The present article re-examines the institute of the provisional stability of the pregnant employee in work contracts for a fixed period in the light of the contractual principles, such as the subjective good faith, the autonomy of the will and the obligatory force of contracts, in order to establish the limits of this provisional stability in the employment. Based on the theory of the dialogue of the sources of Labor Law with Civil Law, it is pointed out that in fixed-term employment contracts, the relative presumption of discriminatory dismissal of the pregnant worker without just cause, in situations of early termination, can be put away if pointed the technical, structural or economic and financial reasons that led to the rupture.
\end{abstract}

Keywords: Stability; Pregnant; Limits; Principles.

\section{RESUMO}

El presente artículo realiza una relectura del instituto de estabilidad provisional de la empleada gestante en los contratos de trabajo por un plazo determinado a la luz de los principios contractuales, como el de la buena fe subjetiva, la autonomía de la voluntad y la fuerza obligatoria de los contratos, para establecer Los límites de esta estabilidad provisional en el empleo. En la teoría del diálogo de las fuentes del Derecho del Trabajo con el Derecho civil, se tiene en los contratos de trabajo por plazo determinado la presunción relativa de despedida discriminatoria de la trabajadora gestante sin justa causa, en situaciones de rescisión anticipada, puede ser alejada desde Que apuntó las razones de orden técnico, estructural o económico-financiero que provocaron la ruptura.

Palabras clave: Estabilidad; Gestora; Límites; Principios 


\section{SUMÁRIO}

INTRODUÇÃO; 1 A FENOMENOLOGIA DA ESTABILIDADE PROVISÓRIA DA EMPREGADA GESTANTE; 20 DIÁLOGO DAS FONTES ENTRE O DIREITO DO TRABALHO E O DIREITO CIVIL; 3 OS LIMITES DA ESTABILIDADE PROVISÓRIA DA GESTANTE NOS CONTRATOS POR PRAZO DETERMINADO; 3.1 Os princípios gerais dos contratos civis: a autonomia da vontade e a boa-fé; 3.20 diálogo da coerência dos princípios da autonomia da vontade e da boa-fé nos contratos de trabalho por prazo determinado; CONCLUSÃO; REFERÊNCIAS.

\section{INTRODUÇÃO}

Ainda no século XXI, são noticiadas situações em que trabalhadoras sofrem discriminação no ambiente de trabalho, por meio de segregação no processo de recrutamento de pessoal, alijamento na execução de determinadas tarefas, ou mesmo com a percepção de remuneração inferior àquelas pagas aos trabalhadores do gênero masculino para a execução da mesma função, dentre outros mecanismos de diferenciação'.

A estabilidade provisória da trabalhadora gestante, desde a confirmação da gravidez até cinco meses após o parto, foi uma das medidas estruturais adotadas pela Constituição Federal de 1988 para a proteção do trabalho da mulher. Mas não apenas a mulher é protegida com a garantia da estabilidade provisória no trabalho. A criança em seu desenvolvimento e formação também tem garantida a sua proteção, como indivíduo sujeito de dignidade, quando é assegurada à trabalhadora gestante a proteção contra a despedida arbitrária.

Ao mesmo tempo em que é assegurada a proteção contra a despedida imotivada da trabalhadora gestante, são reconhecidos no direito contratual os princípios da força obrigatória dos contratos, da autonomia da vontade das partes, manifestada pela liberdade contratual, e da boa-fé objetiva para regular a relação de emprego havida entre empregadores e as trabalhadoras.

O Direito do Trabalho como ramo do direito privado sofre influência direta do Direito Civil, já que grande parte dos princípios do direito contratual irradia e o influencia diretamente, no momento de formação do contrato de trabalho, na fixação das cláusulas contratuais, no cumprimento das obrigações e no encerramento contratual. Ainda que observada a natureza de direito social do Direito do Trabalho, os princípios do Direito Civil influenciam a compreensão das regras deste ramo especializado do Direito.

\footnotetext{
${ }^{1}$ UCHÔA, Marcelo Ribeiro. Mulher e mercado de trabalho no Brasil: um estudo sobre igualdade efetiva baseado no modelo normativo Espanhol. São Paulo: LTr, 2016. p. 91.
} 
O diálogo das fontes do Direito Civil e do Direito do Trabalho é mecanismo hodierno estabelecido na teoria de Erik Jayme ${ }^{2}$ para a solução de eventuais antinomias que possam advir da interpretação dos limites para a resilição unilateral do contrato de trabalho por prazo determinado da empregada gestante. Buscará o presente trabalho, portanto, a partir do diálogo entre as fontes do Direito Civil e do Direito do Trabalho, estabelecer resposta para o seguinte problema de pesquisa: quais são as consequências jurídicas da estabilidade provisória da empregada gestante nos contratos por prazo determinado?

Compreendendo o fenômeno da estabilidade provisória, serão analisados, a partir da revisão da literatura especializada, os efeitos no contrato de trabalho a termo da estabilidade provisória em situações em que tanto a empregada desconhece o estado gravídico no momento da contratação, quanto em situações em que é conhecida no momento da celebração do contrato de trabalho a sua condição de gestante.

\section{A FENOMENOLOGIA DA ESTABILIDADE PROVISÓRIA DA EMPREGADA GESTANTE}

A estabilidade provisória da empregada gestante foi elevada à categoria de direito fundamental das trabalhadoras com a Constituição Federal de 1988, ainda que tal espécie de garantia de emprego tenha sido consagrada topograficamente nos Atos das Disposições Constitucionais Transitórias e não no título específico "Dos direitos e das garantias fundamentais".

O direito, para assumir a natureza jurídica de direito fundamental, deve, além de estar positivado no corpo da Constituição, representar a manifestação direta do princípio matriz da dignidade da pessoa humana. Este princípio fundante do Estado Democrático de Direito expressa que "a dignidade, como qualidade intrínseca da pessoa humana, é algo que simplesmente existe, sendo irrenunciável e inalienável, na medida em que constitui elemento que qualifica o ser humano como tal e dele não pode ser destacado"3.

A natureza de direito fundamental atribuída a um direito decorre, portanto, não apenas do seu aspecto formal, ou seja, de sua positivação por escrito no texto da norma constitucional,

\footnotetext{
2 JAYME, Erik. Identité culturelle et intégration: le droit internacionale privé postmoderne. Recueil des Cours de 1' Académie de Droit Internacional de la Haye, Paris, tomo 251, 1995. p. 60.

3 SARLET, Ingo Wolfgang. A eficácia dos direitos fundamentais: uma teoria geral dos direitos fundamentais na perspectiva constitucional. 10. ed. Porto Alegre: Livraria do Advogado, 2010. p. 100-101.
} 
mas, sobretudo, se seu conteúdo material emanar do princípio da dignidade da pessoa humana ${ }^{4}$. Reconhece-se, assim, a garantia provisória no emprego da trabalhadora gestante a natureza de direito formal e materialmente fundamental.

O direito à estabilidade provisória da trabalhadora gestante objetiva assegurar à trabalhadora a proteção contra a despedida arbitrária ou sem justo motivo no curso do contrato de trabalho. Além de representar mecanismo de proteção à mulher no mercado de trabalho, esta modalidade de estabilidade provisória permite também a proteção do nascituro, enquanto sujeito de direitos, assegurando a este o seu pleno desenvolvimento e segurança, desde a sua concepção.

O sistema de proteção garantido pela estabilidade provisória da trabalhadora gestante é reconhecido como um modelo de proteção dúplice ou ambivalente. 0 sistema protetivo contra a despedida imotivada garante à trabalhadora que esta não venha a ser dispensada sem justa causa desde o momento da confirmação da gravidez até cinco meses após o parto ${ }^{5}$. Representa, assim, a estabilidade provisória da trabalhadora gestante mecanismo de proteção à mulher no mercado de trabalho, sendo manifestação do princípio da solidariedade ${ }^{6}$, impedindo que a empregada, enquanto sujeito de direito titular do direito fundamental à dignidade, venha a sofrer dispensa discriminatória imotivada pelo simples fato de estar grávida. Em outra vertente desse direito fundamental, a garantia da estabilidade provisória à trabalhadora gestante assegura ao nascituro, indiretamente, condições econômicas para que possa se desenvolver com dignidade.

O alcance da estabilidade provisória das gestantes, em um primeiro momento, somente foi garantido às empregadas urbanas, rurais e trabalhadoras avulsas, excluindo-se as empregadas domésticas desta garantia provisória no emprego. Somente a partir da edição da Lei $n^{\circ}$ 11.324/2006 que restou assegurada às empregadas domésticas a garantia provisória do emprego em razão da gestação, corrigindo uma desigualdade histórica, já que a trabalhadora doméstica

\footnotetext{
${ }^{4}$ ALEXY, Robert. Teoria dos direitos fundamentais. Tradução de Virgílio Afonso da Silva. São Paulo: Melhoramentos, 2008. p. 520-523.

${ }^{5}$ Ocorrendo a dispensa imotivada da trabalhadora gestante no período de estabilidade provisória, nos contratos de trabalho por prazo indeterminado, será assegurada preferencialmente a sua reintegração no posto de trabalho ou, sendo a mesma impossível ou inviável, em razão da litigiosidade entre as partes, a medida reintegratória, poderá o Juiz do Trabalho de ofício ou a requerimento proceder a conversão do período remanescente de estabilidade em pagamento de indenização substitutiva. Neste sentido, conferir GAIA, Fausto Siqueira. Tutela inibitória de ofício e a proteção do meio ambiente de trabalho: limites e possibilidades da atuação jurisdicional. São Paulo: LTr, 2015. p. 101-102.

${ }^{6}$ MORAES, Maria Celina Bodin de. O princípio da solidariedade. In: PEIXINHO, Manoel Messias; GUERRA, Isabela Franco; NASCIMENTO FILHO, Firly. (coord.). Os princípios da Constituição de 1988. Rio de Janeiro: Lúmen Juris, 2001. p. 178.
} 
merece igual proteção que às demais trabalhadoras. A Emenda Constitucional $\mathrm{n}^{\circ} 72$ posteriormente alterou o parágrafo único do artigo $7^{\circ}$ da Constituição estendendo às trabalhadoras domésticas o direito à garantia provisória no emprego, dentre outros direitos outrora reconhecidos às trabalhadoras urbanas.

O marco inicial da estabilidade provisória tem início no momento da confirmação do estado gravídico da trabalhadora. A confirmação do estado gestacional constitui ato meramente declaratório da existência do direito ${ }^{7}$, tendo o condão apenas de confirmá-lo. A proteção é da gestação em si, da trabalhadora gestante e do nascituro. Com isso, devem ser repelidas interpretações no sentido de reconhecer que a confirmação da gravidez constituiria o direito em si. Esta distinção se faz importante em razão das consequências jurídicas de se atribuir à confirmação da gravidez a natureza de ato meramente declaratório ou constitutivo do direito à estabilidade provisória.

Ao se reconhecer a confirmação da gravidez como ato declaratório de um fato jurídico, tem-se que o fato do empregador ou mesmo da empregada desconhecer o estado gravídico no curso do contrato de trabalho é irrelevante para fins de assegurar o direito à estabilidade provisória. Por outro lado, em se reconhecendo que a confirmação da gravidez constituiria o direito, o desconhecimento da gestação afastaria o direito à garantia provisória no emprego ${ }^{8}$.

Outro aspecto igualmente relevante que se coloca diz respeito ao momento do conhecimento do estado gravídico, que terá inúmeros impactos na construção teórica que se pretende elaborar acerca do instituto da estabilidade provisória da trabalhadora gestante. Alice Monteiro de Barros 9 , na contramão do entendimento predominante no Tribunal Superior do Trabalho, consolidado na Súmula $\mathrm{n}^{\circ} 244$, defende o posicionamento de que o direito à estabilidade provisória somente é garantido se a trabalhadora tomar conhecimento da gestação na vigência do contrato de trabalho. Esta posição é alicerçada no argumento de que a garantia no emprego dependeria da confirmação da gravidez no curso do contrato de trabalho e, portanto, não teria o condão de desnaturar o ato jurídico perfeito da resilição unilateral do contrato de trabalho se este ato confirmatório vier a ser conhecido após a extinção da relação empregatícia.

\footnotetext{
${ }^{7}$ MARTINS, Nei Frederico Cano. Garantias de emprego: questões controvertidas. Suplemento trabalhista. São Paulo, v. 26, n. 56, 1990. p. 300.

${ }^{8} 0$ Tribunal Superior do Trabalho pacificou entendimento, por meio da Súmula 244 , I, no sentido de reconhecer que o desconhecimento do estado gravídico da empregada por parte do empregador não pode constituir óbice à estabilidade provisória.

${ }^{9}$ BARROS, Alice Monteiro de. Curso de direito do trabalho. 10. ed. São Paulo: LTr, 2016. p. 723.
} 
Esse posicionamento merece reparos, especialmente se considerar que a confirmação da gravidez prevista no texto constitucional refere-se a um ato meramente declaratório e não constitutivo do direito. Não obstante as críticas trazidas a esse posicionamento, veremos em outra seção do nosso trabalho que consequências jurídicas poderão advir do fato das partes do contrato de trabalho por prazo determinado tomarem ciência do estado gravídico da trabalhadora durante ou após a vigência da relação de emprego.

A modalidade de dispensa que se objetiva proteger com a estabilidade provisória da gestante é a imotivada ou sem justa causa. Por outro lado, em havendo configuração da justa causa obreira, por quaisquer das situações elencadas no artigo 482 da CLT, é reconhecida a validade da dispensa da trabalhadora, ainda que durante o período de estabilidade.

Outro ponto que merece ser pontuado, ainda no campo do encerramento do contrato de trabalho, diz respeito a situações de manutenção da estabilidade provisória quando houver o pedido unilateral de resilição do contrato de trabalho por parte da empregada gestante ou de declaração judicial de rescisão indireta, por justa causa cometida pelo empregador. Como já destacado em passagem anterior, o direito à estabilidade provisória é um direito fundamental social da trabalhadora contra a despedida arbitrária ou sem justa causa. Os direitos sociais trabalhistas são reconhecidos como direitos inalienáveis e irrenunciáveis em razão de seu atributo de direito fundamental, associado ao princípio da dignidade da pessoa humana e ao princípio de proteção ao trabalho.

É de se reconhecer que uma parte dos direitos fundamentais não pode ser considerada como direito absoluto, podendo estes direitos reconhecidos na Constituição ser conformados com outros direitos fundamentais individuais e coletivos em uma sociedade. Romita neste sentido estabelece que:

Os direitos só existem no marco de uma sociedade determinada, no seio da qual os seus integrantes são titulares desses direitos. Desta forma, nenhum deles pode valer-se de modo ilimitado sem invadir a esfera de liberdade dos outros indivíduos, ou entrar em rota de colisão com certos valores fundamentais da coletividade. ${ }^{10}$

A abertura de conformação dos direitos fundamentais permite reconhecer que o princípio de proteção ao trabalho da mulher, fundamento axiológico do direito à estabilidade provisória da gestante, quando confrontado com o princípio fundamental da liberdade poderá

${ }^{10}$ ROMITA, Arion Sayão. Direitos fundamentais nas relações de trabalho. 4. ed. São Paulo: LTr, 2012. p. 194. 
estabelecer a regra de decisão no sentido de reconhecer a preponderância na expressão da liberdade da trabalhadora em requerer a resilição unilateral do contrato de trabalho, não obstante the ser assegurada a estabilidade provisória. Os conflitos entre os princípios, diferentemente dos estabelecidos entre as regras, são resolvidos pela regra da ponderação, que poderá apontar no caso concreto uma ou outra decisão igualmente correta ${ }^{11}$.

O conflito entre os mesmos princípios poderão ainda assumir posições distintas em razão das circunstâncias do caso concreto. A liberdade individual, em sua manifestação na esfera contratual, poderá ser reconhecida como princípio preponderante a ser observado se em conflito com o princípio protetivo do trabalho da mulher, quando em análise está a liberdade da trabalhadora gestante requerer a resilição unilateral do contrato de trabalho. Por outro lado, não poderão ser reconhecidas como manifestações da liberdade válidas se a trabalhadora, no momento da contratação, renunciar o princípio protetivo que the assegura a estabilidade provisória.

A norma jurídica de decisão somente pode ser construída no caso concreto, a partir de elementos e demais circunstâncias do cenário fático apresentado. Direito e realidade exercem mútua influência e não se pode desconsiderar a existência do cenário fático quando da construção da norma jurídica no caso concreto ${ }^{12}$.

Essas considerações permitem reconhecer que o direito fundamental à estabilidade provisória da trabalhadora gestante é direito que poderá ser relativizado, diante das circunstâncias fáticas do caso concreto, quando em aparente conflito com outro direito de igual rede de proteção.

Em situações relacionadas à rescisão indireta do contrato de trabalho, onde é reconhecido o cometimento de justa causa por parte do empregador, a legislação consolidada autoriza, de forma excepcional, a continuação ou não da prestação de serviços por parte do empregado, enquanto discutir judicialmente as situações elencadas nas alíneas " $d$ " e " $g$ " do artigo 483, referentes ao descumprimento de obrigações decorrentes do contrato de trabalho e redução do trabalho, por parte do empregador, quando a trabalhadora perceber remuneração por peça ou tarefa.

Ocorrida ou não a descontinuação na prestação de serviços por parte da trabalhadora gestante, e sendo reconhecido o direito à rescisão indireta do contrato de trabalho, há que se garantir o direito à trabalhadora gestante o pagamento de indenização substitutiva da

\footnotetext{
${ }^{11}$ DWORKIN, Ronald. Taking rights seriously. 2. ed. London: Duckworth, 1978. p. 26.

${ }^{12}$ MÜLLER, Friedrich. Teoria estruturante do direito. 3. ed. São Paulo: Revista dos Tribunais, 2011. p. 19.
} 
estabilidade provisória suprimida, sob pena de reconhecer a punição da própria vítima do ato ilícito. Por outro lado, não havendo o reconhecimento judicial da rescisão indireta e tendo a trabalhadora gestante deixado de manter a prestação laboral, será reconhecida a dispensa a pedido da trabalhadora e, consequentemente, não fará jus aos efeitos da garantia provisória de emprego.

A compreensão do fenômeno da estabilidade provisória da trabalhadora gestante deve ser tida a partir da captação da essência ${ }^{13}$ do instituto, que é o da proteção da mulher contra a discriminação no mercado de trabalho. A correta delimitação desse objeto de proteção permitirá distinguir as consequências jurídicas que podem advir nos contratos de trabalho por prazo determinado.

\section{O DIÁLOGO DAS FONTES ENTRE O DIREITO DO TRABALHO E O DIREITO} CIVIL

A regulação das relações empregatícias, por conter em seu bojo direitos fundamentais de natureza social, é mais permeável à influência das regras, princípios e valores constitucionais. O direito material do trabalho é informado por princípios da Constituição, capazes de conformar diretamente a interpretação de suas regras que são de direito privado. A hipossuficiência da trabalhadora gestante no âmbito da relação laboral, na pós-modernidade, exige do aplicador do direito uma leitura valorativa das normas constitucionais, inclusive com a possibilidade de aplicação direta dos direitos fundamentais no âmbito das relações privadas ${ }^{14}$.

A constitucionalização do direito privado, e especialmente no nosso estudo a do direito do trabalho, foi campo fecundo para o desenvolvimento da teoria do Diálogo das Fontes por Erik Jayme $^{15}$, como novo método de interpretação destinado a solucionar de forma coordenada os conflitos de lei no tempo. A teoria do diálogo das fontes apresenta-se como método interpretativo complementar aos tradicionais métodos de solução de antinomias no ordenamento jurídico, como o método da especialidade, método hierárquico e o método cronológico.

\footnotetext{
${ }^{13}$ HUSSERL, Edmund. A crise da humanidade europeia e a filosofia. Tradução de Urbano Zilles. 2. ed. Porto Alegre: EDIPUCRS, 2002. p. 15.

${ }^{14}$ SARMENTO, Daniel. Direitos fundamentais e relações privadas. 2. ed. Rio de Janeiro: Lúmen Juris, 2006. p. 323.

15 JAYME, Erik. Identité culturelle et intégration: le droit internacionale privé postmoderne. Recueil des Cours de 1' Académie de Droit Internacional de la Haye, Paris, tomo 251, 1995. p. 60.
} 
A teoria do diálogo das fontes ganha espaço para aplicação no âmbito das relações de emprego, onde uma das partes, em regra, encontra-se em situação de inferioridade jurídica. A visão de unidade do ordenamento jurídico integrada com princípios específicos do direito material do trabalho, como o princípio da proteção, faz com que a teoria do diálogo das fontes funcione como ferramenta para a efetivação dos direitos metaindividuais trabalhistas, como é o caso do direito fundamental à estabilidade provisória da trabalhadora gestante.

A teoria do diálogo das fontes é apresentada, segundo Cláudia Lima Marques, como "uma tentativa de expressar a necessidade de uma aplicação coerente das leis de direito privado, coexistentes no sistema" ${ }^{16}$, assegurando a todos aqueles que se encontram em posição de vulnerabilidade social uma maior rede de proteção aos seus direitos e interesses jurídicos. No âmbito do Direito do Trabalho, a teoria do diálogo das fontes assume especial relevância, já que a compreensão de unidade do ordenamento jurídico, no paradigma do pós-positivismo jurídico, pode permitir, em matéria de proteção ao trabalho da mulher gestante, a ampliação da rede de proteção às trabalhadoras.

A teoria do diálogo das fontes permite a compreensão do ordenamento jurídico de forma coordenada, com o objetivo de solucionar os eventuais conflitos de normas. No âmbito do direito material do trabalho, a CLT, no parágrafo único do artigo $8^{\circ}$, expressamente autoriza que o Direito Civil ou outras regras do direito comum funcionem como fontes supletivas e subsidiárias às normas trabalhistas, naquilo que não lhe forem incompatíveis com as suas regras e princípios.

A autorização hermenêutica apresentada abriu o caminho para que o intérprete autêntico venha a se utilizar de normas do próprio Direito Civil e de outros ramos do direito público e privado perante as lacunas existentes no sistema trabalhista. 0 espectro de compreensão das lacunas é abrangente e não se limita apenas às chamadas lacunas normativas, ou seja, aquelas em que inexiste norma jurídica apta a regular a situação jurídica posta, mas também situações de lacunas axiológicas e ontológicas, onde, respectivamente, existem normas jurídicas, mas estas geram soluções injustas quando aplicadas ao caso concreto, ou são desatualizadas ${ }^{17}$.

\footnotetext{
${ }^{16}$ BENJAMIN, Antônio Herman V.; MARQUES, Cláudia Lima; BESSA, Leonardo Roscoe. Manual de Direito do Consumidor. 7. ed. São Paulo: Revista dos Tribunais, 2016. p. 141.

${ }_{17}$ Sobre as lacunas jurídicas, Carlos Henrique Bezerra Leite considera a existência de três espécies de lacunas: as lacunas normativas são aquelas em que inexistem normas jurídicas sobre determinado caso, as lacunas ontológicas são aquelas em que há norma jurídica aplicável ao caso, mas ela sofre um processo de envelhecimento em razão do decurso do tempo entre a edição da norma e o momento da aplicação ao caso concreto e as lacunas axiológicas são aquelas existentes quando há norma jurídica, mas ela se revela injusta na aplicação no caso posto. Nesse sentido, conferir LEITE, Carlos Henrique Bezerra. As lacunas do
} 
A teoria do diálogo das fontes é apresentada no neoconstitucionalismo como metodologia hermenêutica que tem como objetivo ampliar a efetividade dos direitos fundamentais dos trabalhadores, superando a desigualdade econômica dos atores da relação de trabalho de modo a alcançar a igualdade jurídica.

A teoria desenvolvida por Erik Jayme na Universidade de Heidelberg manifesta-se por meio de três meios de diálogos entre as fontes do direito, que, segundo a professora Cláudia Lima Marques ${ }^{18}$, são: o diálogo da coerência, o diálogo sistemático da complementariedade ou da subsidiariedade e o diálogo das influências recíprocas sistemáticas.

A manifestação do diálogo da coerência parte do pressuposto da coexistência de duas normas jurídicas, onde uma delas, de caráter geral, serve como alicerce para a outra norma jurídica de caráter específico, cujo campo de aplicação é restrito a um determinado grupo social ou categoria jurídica ou econômica. É representado este mecanismo de diálogo por meio da relação envolvendo as normas gerais e as normas especiais, onde aquelas apresentam os contornos normativos mais genéricos que devem ser observados pelas normas específicas.

De modo a demonstrar a aplicação do diálogo da coerência, tem-se os princípios gerais do Direito Civil da boa-fé objetiva e do equilíbrio dos contratantes, que constituem elementos interpretativos gerais do Direito Civil e que são aplicáveis inclusive em relações jurídicas específicas, como são exemplos as relações de emprego e as consumeristas. Ainda que inexistam normas jurídicas que tratem, especificamente, da aplicação desses princípios aos contratos de trabalho, ou seja, situação específica de lacuna jurídica na legislação especial, há que se reconhecer a aplicação dessa manifestação do diálogo das fontes para permitir ao operador do direito interpretar as regras do contrato de trabalho à luz deste princípio geral do Direito Civil.

Outra forma de apresentação do diálogo das fontes ocorre por meio do diálogo sistemático da subsidiariedade ou da complementariedade. A aplicação dessa manifestação do diálogo das fontes pressupõe o reconhecimento de que o ordenamento jurídico deve ser compreendido como um todo unitário. Permite-se, desta forma, ao aplicador do direito no caso concreto, perante uma lacuna normativa, ontológica ou mesmo axiológica, que se valha da aplicação de outra fonte do direito para complementar a aplicação do direito.

direito do trabalho e a necessidade de heterointegração (diálogo das fontes) com o direito civil. In: ALMEIDA, Renato Rua de (coord.); CALVO, Adriana (assistente de coordenação). Aplicação da teoria do diálogo das fontes no direito do trabalho. São Paulo: LTr, 2015. p. 49.

${ }^{18}$ BENJAMIN, Antônio Herman V.; MARQUES, Cláudia Lima; BESSA, Leonardo Roscoe. Manual de Direito do Consumidor. 7. ed. São Paulo: Revista dos Tribunais, 2016. p. 143-144. 
O diálogo das influências recíprocas sistemáticas é a terceira forma de manifestação da teoria do diálogo das fontes. A aplicação desse método interpretativo reconhece a existência de influências mútuas entre dois ou mais sistemas jurídicos, tanto do geral no especial, quanto do especial no geral, em via de duplo sentido.

A condição de hipossuficiente da empregada gestante e a necessidade de garantir a máxima efetividade do princípio constitucional da proteção demandam do intérprete autêntico ${ }^{19}$ a apropriação dos princípios e das regras de outros ramos do direito, como é o caso do Direito Civil, em busca de uma solução coerente e justa para o caso concreto.

A aplicação prática da teoria do diálogo das fontes revela mecanismo importante na tarefa de solucionar os conflitos de normas, especialmente diante das controvérsias existentes acerca da coexistência da estabilidade provisória da trabalhadora gestante e os contratos de trabalho por prazo determinado, conforme será analisado nas próximas etapas desse trabalho.

\section{OS LIMITES DA ESTABILIDADE PROVISÓRIA DA GESTANTE NOS CONTRATOS POR PRAZO DETERMINADO}

Serão analisados a seguir os limites da estabilidade provisória da gestante nos contratos de trabalho por prazo determinado à luz da teoria do diálogo das fontes.

Para tanto, em razão da dimensão irradiadora hermenêutica dos princípios do Direito Civil no Direito do Trabalho, serão apreciados os princípios da autonomia da vontade e o da boafé para, finalmente, a partir do diálogo da coerência, compreender os limites da estabilidade provisória da trabalhadora gestante nos contratos por prazo determinado.

\subsection{Os princípios gerais dos contratos civis: a autonomia da vontade e a boa-fé}

Os princípios da autonomia da vontade das partes, da força obrigatória dos contratos, da relatividade dos seus efeitos, da revisão por onerosidade excessiva, da função social e da boa-fé objetiva e subjetiva, informam o direito contratual civil e exercem influência na interpretação dos contratos de trabalho, desde o momento da sua formação até o seu encerramento.

${ }^{19}$ KELSEN, Hans. Teoria pura do direito. Tradução de João Baptista Machado. 6. ed. São Paulo: Martins Fontes, 1998. p. 394. 
A formação do contrato de trabalho, em razão de seu caráter especial de contrato privado, sofre conformação direta desses princípios informadores do Direito Civil. Em razão da delimitação do objeto de pesquisa, relativa à garantia da estabilidade provisória das trabalhadoras gestantes nos contratos a termo ou por prazo determinado, os princípios da autonomia da vontade e da boa-fé serão delineados de forma pormenorizada, já que impactam diretamente a interpretação acerca desta garantia constitucional.

Os princípios funcionam como elementos fundantes do sistema jurídico, capazes de assegurar a plasticidade ao sistema quanto à adequação do direito ao fato social a ser regulado. Funcionam os princípios, dentre outros papeis ${ }^{20}$, como verdadeiros vetores interpretativos, que devem ser conformados pelo aplicador do direito no caso concreto. Humberto Ávila aponta que os princípios são:

[...] normas imediatamente finalísticas, primariamente prospectivas e com pretensão de complementariedade e de parcialidade, para cuja aplicação se demanda uma avaliação da correlação entre o estado de coisas a ser promovido e os efeitos decorrentes da conduta havida como necessária a sua promoção. ${ }^{21}$

Os princípios contratuais do Direito Civil funcionam como normas gerais, que a partir do diálogo da coerência, influenciam diretamente a interpretação dos contratos de trabalho, como espécie do gênero contrato privado.

O princípio da autonomia da vontade tem sua matriz no direito fundamental da liberdade. A liberdade na seara contratual sofre influência direta da acepção liberal do princípio da liberdade de cunho negativo, assegurando às partes livremente a pactuação dos direitos e obrigações que regerão a relação contratual ${ }^{22}$. A liberdade contratual manifestada pelo princípio da autonomia da vontade não é ilimitada, podendo sofrer restrições interpretativas em razão de normas de ordem pública, que funcionam como regras ou princípios de barreira, ou mesmo quando em confronto com outro direito fundamental no caso em concreto.

As partes no contrato de trabalho possuem, em regra, liberdade para o estabelecimento das cláusulas contratuais relativas à sua vigência ou duração. 0 direito do trabalho é informado

\footnotetext{
${ }^{20}$ Dentre as outras funções dos princípios estão a de servir como instrumento para a colmatação de lacunas, bem como funcionam como instrumentos a serem observados pelo órgão legislador na elaboração dos textos das normas jurídicas.

21 ÁVILA, Humberto. Teoria dos princípios: da definição à aplicação dos princípios jurídicos. 14. ed. São Paulo: Malheiros, 2013. p. 85.

22 LIPPMAN, Ernesto. Os direitos fundamentais da Constituição de 1988 com anotações e jurisprudência dos tribunais. São Paulo: LTr, 1999. p. 64.
} 
pelo princípio da continuidade da relação de emprego, o que significa reconhecer que a relação trabalhista prima pela sua manutenção no tempo, inserindo o trabalhador na empresa.

Os contratos de trabalho em sua essência vigem por prazo indeterminado como regra geral. A contratação a termo ou por prazo determinado é excepcional, sendo autorizada em determinadas situações previstas pelo legislador ordinário, como são as situações dos contratos de experiência, com duração máxima de 90 dias, ou daqueles em que o trabalhador é contratado para serviços cuja transitoriedade ou natureza justifique a predeterminação de um prazo ou para atividades empresariais de caráter transitório, observada nestas duas últimas situações a duração máxima de dois anos.

A autonomia da vontade das partes nos contratos por prazo determinado sofre restrição em razão das normas de ordem pública previstas na legislação consolidada. O princípio da proteção funciona como instrumento limitador do princípio da liberdade contratual. A contratação por prazo determinado representa manifestação da autonomia da vontade das partes que, observadas as limitações quanto à duração e hipóteses de cabimento previstas na legislação consolidada, deve ser considerada lícita.

O princípio da boa-fé é outro princípio informador do direito contratual, que exerce importante influência na interpretação dos contratos, especialmente dos contratos de trabalho. O princípio da boa-fé é manifestado pelo dever de transparência e de lealdade que é exigido das partes, seja no momento da fixação das cláusulas dos contratos, durante o seu cumprimento, ou mesmo após o encerramento, inclusive podendo ser exigido após o encerramento da relação jurídica ${ }^{23}$.

A boa-fé objetiva representa verdadeiro padrão de comportamento ético ou standard objetivo que deve ser observado pelas partes, de forma independente do polo que ocupa na relação contratual. A boa-fé objetiva representa, portanto:

uma atuação "refletida", uma atuação refletindo, pensando no outro, no parceiro contratual, respeitando-o, respeitando seus interesses legítimos, suas expectativas razoáveis, seus direitos, agindo com lealdade, sem abuso, sem obstrução, sem causar lesão ou desvantagem excessiva, cooperando para atingir o bom final das obrigações: o cumprimento do objetivo contratual e a realização dos interesses das partes. ${ }^{24}$

\footnotetext{
${ }^{23}$ A cláusula contratual de sigilo e confidencialidade do contrato, uma das manifestações do princípio da boa-fé contratual, pode ser licitamente pactuada entre as partes, inclusive com a possibilidade de sua manutenção após o termo final do contrato.

${ }^{24}$ MARQUES, Cláudia Lima. Contratos no código de defesa do consumidor: o novo regime das relações contratuais. 4. ed. São Paulo: Revista dos Tribunais, 2004. p. 181.
} 
Ao lado do padrão geral de comportamento, que deve ser exigido pelas partes do contrato, a boa-fé também se manifesta em seu aspecto subjetivo. A boa-fé subjetiva ou boa-fé crença é representada pelo comportamento praticado pelas partes, a partir do elemento anímico, ainda que não seja do seu conhecimento por negligência ou outra forma de manifestação culposa da parte do contrato. A boa-fé subjetiva tem como seu contraposto a máfé.

A fixação dos contornos destes dois princípios gerais do direito contratual permite a delimitação dos contornos que devem ser observados pelo intérprete autêntico diante do reconhecimento da estabilidade provisória das trabalhadoras gestantes, nos contratos por prazo determinado, o que será a seguir analisado.

\subsection{0 diálogo da coerência dos princípios da autonomia da vontade e da boa-fé nos contratos de trabalho por prazo determinado}

A formação do contrato de trabalho concretiza a manifestação do princípio da autonomia da vontade das partes. É exigido das partes do contrato de trabalho, durante toda a vigência da relação empregatícia, o cumprimento dos deveres de probidade e de boa-fé.

O contrato na relação de emprego é firmado em regra por partes que ostentam situações econômico-jurídicas distintas, o que influencia o poder de negociação das cláusulas contratuais que o regerão. 0 contrato de trabalho é apresentado, mutatis mutandis, na forma de um contrato de adesão, onde a interpretação de suas cláusulas deve observar a desigualdade material entre os celebrantes.

A fixação da cláusula de duração do contrato de trabalho, como analisada anteriormente, não é de livre estipulação entre os contratantes na relação de emprego, ante a fixação de regras de ordem pública decorrentes dos princípios protetivo e da continuidade da relação de emprego. A predeterminação da vigência do contrato é estabelecida ex lege, sem que as partes tenham autonomia para majorar os prazos máximos fixados para a duração das avenças, ou mesmo constituindo hipóteses de celebração diversas daquelas que a lei autoriza.

As modalidades de contrato a termo, ou por prazo determinado, em razão das diferentes situações que autorizam a sua celebração, devem sofrer consequências jurídicas próprias nas situações envolvendo a estabilidade provisória da trabalhadora gestante. 
O Tribunal Superior do Trabalho, em setembro de 2012, alterou a redação da Súmula 244, fixando interpretação no sentido de assegurar a estabilidade provisória à trabalhadora gestante nos contratos a termo ou por prazo determinado. A regra geral, portanto, é no sentido de se reconhecer a garantia provisória no emprego nos contratos, ainda que os mesmo tenham prefixação dos prazos de duração.

Os precedentes que permitiram a fixação desse entendimento jurisprudencial, a exemplo dos julgamentos da $1^{\text {a }}$ Turma nos Recursos de Revista $n^{\circ}$ 001601-11-2010.5.09.0068 ${ }^{25} \mathrm{e}$ 00107-20.2011.5.18.0006 ${ }^{26}$, limitaram-se a reconhecer o direito à estabilidade provisória das trabalhadoras gestantes nos contratos a termo a partir de uma única razão de decidir, qual seja a condição de gestante da trabalhadora no momento da rescisão contratual. Os julgamentos que ensejaram a reformulação da redação da Súmula 244 do TST deixaram de enfrentar questões fáticas do caso em concreto, em razão da própria limitação quanto à apreciação destas matérias nos julgamentos dos recursos de revista, que permitiriam a formulação de outra norma de decisão ou Entscheidungsnorm ${ }^{27}$.

A análise dos precedentes da Súmula $n^{\circ} 244$ do TST permite a formulação de norma de decisão, afastando a sua aplicação no caso concreto, desde que presentes situações fáticas especiais decorrentes do contrato de trabalho a termo firmado entre o empregador e a trabalhadora gestante.

Como vimos, uma das situações previstas pelo legislador que autoriza a celebração do contrato por prazo determinado é a situação do contrato de experiência ou de prova. 0 contrato de experiência tem duração máxima autorizada de até 90 dias, podendo ser celebrado por menor prazo, prorrogável até este limite temporal.

${ }^{25}$ BRASIL. Tribunal Superior do Trabalho. Recurso de Revista $n^{\circ}$ TST-RR-1601-11.2010.5.09.0068. Angelica Fabiana da Silva e Confexforte Indústria e Comércio Ltda. Relator: Ministro Vieira de Mello Filho. 29 fevereiro de $2012 . \quad$ Disponível em: http: / / aplicacao5.tst.jus.br/consultaunificada2/inteiroTeor.do?action=printInteiroTeor\&highlight=true\&n umeroFormatado=RR\%20-\%201601-

11.2010.5.09.0068\&base $=$ acordao $\mathrm{n}$ numProclnt $=93967 \&$ anoProclnt $=2011 \&$ dataPublicacao $=09 / 03 / 2012 \% 200$ 7:00:00\&query. Acesso em: 20 jul. 2017.

${ }^{26}$ BRASIL. Tribunal Superior do Trabalho. Recurso de Revista $n^{\circ}$ TST-RR-107-20.2011.5.18.0006. Silvania Pereira de Brito e Turqueza Tecidos e Vestuários Ltda. Relator: Ministro Walmir Oliveira da Costa. 07 de dezembro de 2011. Disponível http://aplicacao5.tst.jus.br/consultaunificada2/inteiroTeor.do?action=printInteiroTeor\&highlight=true\&n umeroFormatado=RR\%20-\%20107-

20.2011.5.18.0006\&base $=$ acordao \&numProcInt $=125342 \&$ anoProclnt $=2011 \&$ dataPublicacao $=16 / 12 / 2011 \% 20$ 07:00:00\&query=. Acesso em: 20 jul. 2017.

27 ADEODATO, João Maurício. Norma jurídica como decisão dotada de efetividade. Revista Jurídica da Presidência, Brasília, v. 15, n. 106, jun./set. 2013. p. 313. 
A essência do contrato de experiência é o de assegurar ao empregador a verificação do desempenho do empregado contratado, inclusive suas aptidões e produtividade no exercício da função. De outro lado, permite-se ao trabalhador, durante o período de prova, avaliar as condições efetivas de labor, para ao final do período de experiência decidir pela continuidade ou não da prestação de serviços.

A análise fenomenológica do contrato de experiência traz como essência desta modalidade contratual a aferição das efetivas condições de trabalho, tanto por parte do trabalhador, quanto do empregado. Essa circunstância fática é importante quando da análise de se reconhecer a garantia no emprego à trabalhadora gestante contratada a termo ou por prazo determinado.

Não apenas este elemento deve ser observado na formulação da norma de decisão. Fora destacado na primeira seção deste artigo que a norma que assegura à trabalhadora a estabilidade provisória no emprego tem como essência servir de norma de proteção contra a discriminação da mulher no mercado de trabalho, impedindo que a mesma seja dispensada em razão da condição de trabalhadora gestante. A compreensão da estabilidade provisória da empregada gestante no contrato de experiência, portanto, deve contemplar não apenas o estado gravídico da trabalhadora no momento da resilição contratual, mas também se a despedida, no caso concreto, foi expressão de ato discriminatório praticado pelo empregador.

Para tanto, outro elemento circunstancial deve ser observado pelo intérprete autêntico no momento da formulação da norma de decisão: o conhecimento do estado gravídico no momento da celebração do contrato de trabalho. Além disso, a compreensão dialogada entre as fontes do Direito do Trabalho e do Direito Civil Contratual permitirá a confecção da correta norma de decisão.

O contrato de trabalho é informado, dentre outros princípios, pela autonomia da vontade e pela boa-fé. Uma vez desconhecida pelo empregador a gravidez da empregada no momento da contratação, milita em favor desta parte do contrato a presunção relativa de que o encerramento da relação de emprego no termo final do contrato de experiência foi medida discriminatória.

Por outro lado, sabido pelo empregador o estado gravídico da trabalhadora no momento da celebração do contrato de experiência, milita em favor do detentor dos meios de produção a presunção relativa de que a ruptura contratual, no termo final do contrato de experiência, não teve o aspecto discriminatório. Defende-se, no entanto, em razão dos princípios trabalhistas da proteção e da continuidade da relação de emprego, e de um dos aspectos da essência do 
contrato de experiência, que é a verificação da aptidão da empregada para o trabalho, que terá o empregador o dever jurídico de apresentar as razões de ordem técnica, estrutural ou econômico-financeira que ensejaram a ruptura da relação contratual, sob pena de se reconhecer a prática de ato discriminatório.

Para elidir esta presunção nas duas situações apresentadas, e, consequentemente, afastar o direito à estabilidade provisória no emprego, deverá o empregador demonstrar a inaptidão da obreira no período de experiência ou de prova, como manifestação do princípio contratual da boa-fé. Será atendido, assim, não apenas o princípio da boa-fé contratual, mas também se privilegiará o da autonomia da vontade das partes no momento da celebração do contrato a termo.

Em relação às demais hipóteses de autorização de contrato de trabalho por prazo determinado, para atender necessidade temporária de serviço ou para situações em que a atividade empresarial tenha duração transitória, circunstâncias outras devem ser consideradas na formulação da norma de decisão, a partir do diálogo entre os princípios do Direito do Trabalho e os princípios da autonomia da vontade e da boa-fé.

Nas situações envolvendo necessidade temporária de serviço, como é o exemplo da celebração de contratos de trabalho no comércio em épocas festivas de maior movimento de vendas, ou mesmo quando a atividade empresarial tem duração limitada no tempo, como é o caso de feiras de eventos, estando estipulada no contrato de trabalho a circunstância fática que determinou a contratação, milita em favor do empregador a presunção de que a dispensa ocorrida no seu termo final não foi obstativa da estabilidade provisória. Assegura-se, assim, a eficácia dos princípios da autonomia da vontade e da boa-fé. Poderá, entretanto, a empregada gestante dispensada demonstrar o ato discriminatório e assim garantir o direito à estabilidade provisória, em situações em que as circunstâncias fáticas que determinaram a contratação permaneçam após a resilição do contrato de trabalho.

Por fim, em havendo a rescisão antecipada do contrato a termo ou por prazo determinado, em quaisquer situações autorizadas por lei para a sua celebração, militará em favor da empregada grávida a presunção também relativa de despedida obstativa do direito à garantia provisória no emprego. Competirá ao empregador demonstrar, no caso do contrato de experiência, a inaptidão da trabalhadora para a função, e, nas situações envolvendo o atendimento de necessidade temporária de serviço ou para situações em que a atividade empresarial tenha duração transitória, a demonstração das questões de ordem técnica, estrutural ou econômico-financeira que ensejaram a ruptura da relação contratual precoce. 


\section{CONCLUSÃO}

O paradigma do pós-positivismo jurídico tem a centralidade da Constituição e a força normativa dos seus princípios estruturantes como base central no processo de interpretação e de construção do direito. A fenomenologia da estabilidade provisória da trabalhadora gestante deve ser compreendida a partir da sua essência, que é a de tutelar tanto a mulher no mercado de trabalho, quanto assegurar o desenvolvimento saudável do nascituro.

A teoria do diálogo das fontes é apresentada, neste contexto, como instrumento interpretativo para solucionar conflito aparente de normas, complementando métodos tradicionais de solução de antinomias jurídicas.

A compreensão da garantia provisória do emprego da trabalhadora gestante nos contratos por prazo determinado deve ser analisada não apenas observando o elemento objetivo, que é o estado gravídico da empregada no momento da extinção do contrato de trabalho, mas, sobretudo, observando as circunstâncias fáticas do caso concreto, que permitirão a construção da norma de decisão correta.

Nos contratos a termo ou celebrados por prazo determinado, em razão do diálogo entre os princípios protetivos, da continuidade da relação de emprego e o da boa-fé, milita em favor da trabalhadora gestante a presunção de despedida discriminatória, nas situações envolvendo a rescisão antecipada.

Havendo a extinção do contrato de trabalho em seu termo final, competirá ao empregador nos contratos de experiência apresentar as razões de ordem técnica, estrutural ou econômico-financeira que ensejaram a ruptura. Já nas demais situações autorizativas para a celebração de contratos a termo, será da trabalhadora gestante o ônus probatório de demonstrar o ato discriminatório do empregador.

\section{REFERÊNCIAS}

ADEODATO, João Maurício. Norma jurídica como decisão dotada de efetividade. Revista Jurídica da Presidência, Brasília, v. 15, n. 106, p. 307-335, jun./set. 2013.

ALEXY, Robert. Teoria dos direitos fundamentais. Tradução de Virgílio Afonso da Silva. São Paulo: Melhoramentos, 2008. 
ÁVILA, Humberto. Teoria dos princípios: da definição à aplicação dos princípios jurídicos. 14. ed. São Paulo: Malheiros, 2013.

BARROS, Alice Monteiro de. Curso de direito do trabalho. 10. ed. São Paulo: LTr, 2016.

BENJAMIN, Antônio Herman V.; MARQUES, Cláudia Lima; BESSA, Leonardo Roscoe. Manual de Direito do Consumidor. 7. ed. São Paulo: Revista dos Tribunais, 2016.

BRASIL. Tribunal Superior do Trabalho. Recurso de Revista $n^{\circ}$ TST-RR-107-20.2011.5.18.0006. Silvania Pereira de Brito e Turqueza Tecidos e Vestuários Ltda. Relator: Ministro Walmir Oliveira da Costa. 07 de dezembro de 2011. Disponível em:

http: //aplicacao5.tst.jus.br/consultaunificada2/inteiroTeor.do?action=printInteiroTeor\&highligh $\mathrm{t}=$ true\&numeroFormatado=RR\%20-\%20107-

20.2011.5.18.0006\&base $=$ acordao\&numProc Int $=125342 \&$ anoProc $\operatorname{lnt}=2011 \&$ dataPublicacao $=16 / 12$ 12011\%2007:00:00\&query $=$. Acesso em: 20 jul. 2017.

BRASIL. Tribunal Superior do Trabalho. Recurso de Revista $\mathbf{n}^{\circ}$ TST-RR-1601-

11.2010.5.09.0068. Angelica Fabiana da Silva e Confexforte Indústria e Comércio Ltda. Relator: Ministro Vieira de Mello Filho. 29 de fevereiro de 2012. Disponível em:

http://aplicacao5.tst.jus.br/consultaunificada2/inteiroTeor.do?action=printInteiroTeor\&highligh $\mathrm{t}=$ true\&numeroFormatado=RR\%20-\%201601-

11.2010.5.09.0068\&base $=$ acordao\&numProc Int $=93967 \&$ anoProc $\ln t=2011 \&$ dataPublicacao $=09 / 03 /$ 2012\%2007:00:00\&query. Acesso em: 20 jul. 2017.

DWORKIN, Ronald. Taking rights seriously. 2. ed. London: Duckworth, 1978.

GAIA, Fausto Siqueira. Tutela inibitória de ofício e a proteção do meio ambiente de trabalho: limites e possibilidades da atuação jurisdicional. São Paulo: LTr, 2015.

HUSSERL, Edmund. A crise da humanidade europeia e a filosofia. Tradução de Urbano Zilles. 2. ed. Porto Alegre: EDIPUCRS, 2002.

JAYME, Erik. Identité culturelle et intégration: le droit internacionale privé postmoderne.

Recueil des Cours de 1' Académie de Droit Internacional de la Haye, Paris, tomo 251, 1995. KELSEN, Hans. Teoria pura do direito. Tradução de João Baptista Machado. 6. ed. São Paulo: Martins Fontes, 1998.

LEITE, Carlos Henrique Bezerra. As lacunas do direito do trabalho e a necessidade de heterointegração (diálogo das fontes) com o direito civil. In: ALMEIDA, Renato Rua de (coord.); CALVO, Adriana (assistente de coordenação). Aplicação da teoria do diálogo das fontes no direito do trabalho. São Paulo: LTr, 2015.

LIPPMAN, Ernesto. Os direitos fundamentais da Constituição de 1988 com anotações e jurisprudência dos tribunais. São Paulo: LTr, 1999.

MARQUES, Cláudia Lima. Contratos no código de defesa do consumidor: o novo regime das relações contratuais. 4. ed. São Paulo: Revista dos Tribunais, 2004. 


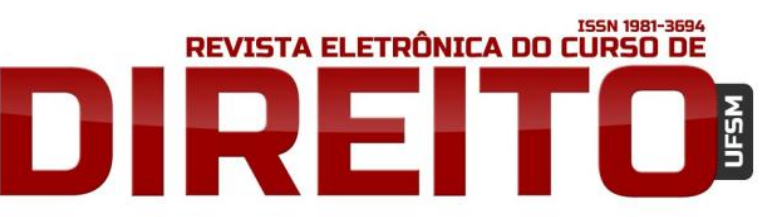

A ESTABILIDADE PROVISÓRIA DA GESTANTE E O DIÁLOGO DA COERÊNCIA: UMA COMPREENSÃO FENOMENOLÓGICA

FAUSTO SIQUEIRA GAIA

MARTINS, Nei Frederico Cano. Garantias de emprego: questões controvertidas. Suplemento trabalhista, São Paulo, v. 26, n. 56, 1990.

MORAES, Maria Celina Bodin de. O princípio da solidariedade. In: PEIXINHO, Manoel Messias; GUERRA, Isabela Franco; NASCIMENTO FILHO, Firly. (coord.). Os princípios da Constituição de 1988. Rio de Janeiro: Lúmen Juris, 2001.

MÜLLER, Friedrich. Teoria estruturante do direito. 3. ed. São Paulo: Revista dos Tribunais, 2011.

ROMITA, Arion Sayão. Direitos fundamentais nas relações de trabalho. 4. ed. São Paulo: LTr, 2012.

SARLET, Ingo Wolfgang. A eficácia dos direitos fundamentais: uma teoria geral dos direitos fundamentais na perspectiva constitucional. 10. ed. Porto Alegre: Livraria do Advogado, 2010.

SARMENTO, Daniel. Direitos fundamentais e relações privadas. 2. ed. Rio de Janeiro: Lúmen Juris, 2006.

UCHÔA, Marcelo Ribeiro. Mulher e mercado de trabalho no Brasil: um estudo sobre igualdade efetiva baseado no modelo normativo Espanhol. São Paulo: LTr, 2016.

Recebido em: 07/01/2017 / Revisões requeridas em: 20/04/2017 / Aprovado em: 27/04/2017

\section{COMO CITAR O ARTIGO (ABNT)}

GAIA, Fausto Siqueira. A ESTABILIDADE PROVISÓRIA DA GESTANTE E O DIÁLOGO DA COERÊNCIA: UMA COMPREENSÃO FENOMENOLÓGICA. Revista Eletrônica do Curso de Direito da UFSM, Santa Maria, RS, v. 12, n. 2, p. 497-516, ago. 2017. ISSN 1981-3694. Disponível em: <https://periodicos.ufsm.br/revistadireito/article/view/25518>. Acesso em: dia mês. ano. doi:http://dx.doi.org/10.5902/1981369425518. 